University of Nebraska - Lincoln

DigitalCommons@University of Nebraska - Lincoln

Management Department Faculty Publications

Management Department

2013

\title{
The Importance of Developing Employability
}

Peter D. Harms

University of Nebraska - Lincoln, pharms@gmail.com

Bradley J. Brummel

University of Tulsa, bradley-brummel@utulsa.edu

Follow this and additional works at: https://digitalcommons.unl.edu/managementfacpub

Harms, Peter D. and Brummel, Bradley J., "The Importance of Developing Employability" (2013).

Management Department Faculty Publications. 105.

https://digitalcommons.unl.edu/managementfacpub/105

This Article is brought to you for free and open access by the Management Department at DigitalCommons@University of Nebraska - Lincoln. It has been accepted for inclusion in Management Department Faculty Publications by an authorized administrator of DigitalCommons@University of Nebraska - Lincoln. 
Published in Industrial and Organizational Psychology: Perspectives on Science and Practice 6:1 (March 2013), pp. 20-24; doi: 10.1111/iops.12003

Copyright @ 2013 Society for Industrial and Organizational Psychology. Published by John Wiley \& Sons/Blackwell. Used by permission.

Published online February 12, 2013.

\title{
The Importance of Developing Employability
}

\author{
P. D. Harms, University of Nebraska-Lincoln
}

Bradley J. Brummel, The University of Tulsa

Corresponding author - P. D. Harms, University of Nebraska-Lincoln, 265 CBA, 1240 R Street, Lincoln, NE 68588; email pharms2@unl.edu

The focal article by Hogan, Chamorro-Premuzic, and Kaiser is timely. With persistently high unemployment levels in the United States and across the globe it is clear that we need not only an understanding of what makes people successful in the jobs that they have but also an understanding of how to get them into the workforce and keep them there. To make the problem even clearer, consider the fact that despite the high unemployment rates and increasing numbers of students attending college, there are an estimated 3.5 million unfilled job openings (http://www.bls.gov/news.release/jolts.nr0.htm) at this very moment. Industrial-organizational (I-O) psychologists need to come to a better understanding of the nature of this problem and the potential solutions. The focal article represents an important first step in this process, but we believe that there are some areas of neglect in the model presented. In particular, we would like to focus our commentary on the development of both character and knowledge, skills, and abilities necessary for employment.

Hogan et al. (2013) describe employability as being based not only on KSAs but also aspects of character such as personal ambition, the willingness to work hard, and social skills. They rightly conclude that both KSAs and character can be developed and suggest that educational experi- 
ences be targeted at developing these skills and traits. We would like to make the additional argument that work experiences themselves are an important driver of not only KSAs but also character traits.

\section{Developing Employability}

As a field, I-O psychologists are comfortable with the idea that the KSAs needed to be able to do a job can be developed. Training, both within organizations and in our education system, has been aligned to develop an individual's ability to do the job of their choosing. However, comparatively little effort has been made to understand the mechanisms by which interpersonal skills and a willingness to engage in hard work can be developed. Although there is a broad literature on character development and maturity, we have not systematically incorporated this work into our approaches to employability. We believe that Hogan et al.'s model gives us a foundation for these efforts. Specifically, it suggests that we rebalance the amount of attention paid to evaluating and developing each of the fundamental aspects of employability.

Sociological models tell us that both life experiences (e.g., growing up in a family with greater financial resources) and expectations (e.g., having parents communicate their aspirations for a child's eventual career-level) are key drivers of eventual success in the working world (Sewell and Hauser, 1980, 1992). However, these developmental antecedents are routinely modeled as leading to educational success, which is then used to predict eventual career success (e.g., Haller \& Portes, 1973). Hogan et al. follow in this tradition in that they limit discussion of developmental processes to those that occur before an individual enters the workplace, primarily education experiences. We argue that an appreciation of the developmental processes both in and out of the workplace beyond the college years is fundamental to understanding employability and could transform practice in terms of both selection and training as well as governmental policy.
That work experiences can drive character development is now well-established in the personality literature (Hudson, Roberts, \& Lodi-Smith, 2012; Roberts, 1997; Roberts, Caspi, \& Moffitt, 2003). For example, in an 8-year longitudinal study of young, working adults, Roberts et al. (2003) found that having greater amounts of autonomy and resource power on the job is associated with positive changes in social potency, well-being, and achievement. Moreover, organizational culture can impact development above and beyond the impact of unique individual experiences. For example, individuals operating in highly competitive cultures have been shown to decrease in trait Agreeableness (Roberts \& Robins, 2004) whereas those in organizations characterized by a highly intellectual environment tend to experience increases in trait Openness (Harms, Roberts, \& Winter, 2006). Roberts and his colleagues have referred to these findings as the corresponsive principle. That is, the characteristics that enable an individual to be successful in a given environment will be the characteristics that will be reinforced in that environment.

A second work-related developmental force, the social investment principle, also warrants mention in terms of understanding the role of personality development and employability. This principle postulates that positive personality development occurs in response to increased social investment in institutions such as work, religion, marriage, and family life (Roberts \& Wood, 2006). A recent meta-analysis testing this principle found that investment in work, as characterized by increased engagement and performance was associated with increases in Agreeableness, Conscientiousness, and Emotional Stability (Lodi-Smith \& Roberts, 2007). In addition to this, there is evidence that de-investment from work is also associated with personality changes. For example, a history of engaging in counter-productive work behaviors has been shown to be related to negative changes in Emotional Stability, Agreeableness, and Conscientiousness (Hudson et al. 2012; Roberts, Bogg, Walton, \& Caspi, 2006). 
These findings are even more disturbing in light of the lingering problem of unemployment and underemployment that the economy is facing today. Millions of people, particularly young adults, are not receiving the positive developmental effects of social investment that they would otherwise obtain because they have not secured long-term, stable employment. Moreover, there is evidence that a history of job instability is related to negative personality development, particularly in older workers. For example, using unpublished data provided to us by Hogan Assessment Systems, we have found that frequently unemployed individuals are characterized by decreasing levels of ambition and adjustment. We believe that this is partially due to the fact that these individuals redefine their identity based on their experiences of failure in the world of work (Paul \& Moser, 2009; United Nations Development Programme, 2006, p. 35). That is, they come to see themselves as socially excluded failures and are more prone to giving up in the face of obstacles. Those who end up being put on disability benefits may experience even greater psychological despair after being categorized as "broken" and may never return to the workforce.

\section{Leveraging an Understanding of Personality Development for Employability}

We believe that understanding how work experiences can contribute to personality change necessary for employability has implications for how business, society, and I-O psychology approach the problem of employability.

Business implications - Although I-O psychologists primarily focus training efforts on developing KSAs, there is some acknowledgement that soft skills and patterns of behaviors can be trained through a variety of interventions (e.g., executive coaching, special assignments for high potentials, and developmental assessment centers). However, these interventions are typically reserved for the best, most upwardly mobile employees rather than those trying to find employment. Personality is rarely mentioned as a developmental target because psychologists have generally treated it as an unchanging exogenous variable. Yet, as we have seen, this perception does not reflect empirical findings to date. Once we break free of the notion of trait fixedness and begin using the language of change, we expect to see changes in how businesses approach both selection and assessment. For example, rather than selecting individuals based on their current standing on a variety of traits and abilities, organizations could integrate the likelihood of or propensity for development into their decision making. Put in the terms of a regression model, rather than selecting for an intercept, one could select based on intercept and slope with the aim at choosing the higher performer in the long term. This might include selecting for willingness to develop or selecting someone without needed KSAs who has demonstrated the ability to work hard. We believe that this goal is ultimately where many $\mathrm{I}-\mathrm{O}$ psychologists and organizations will find value in the model put forward by Hogan et al.

Societal implications - The problem of employability has implications for how broader society consumes educational experiences as well. Numerous recent reports show that more than half of individuals graduating with undergraduate degrees are underemployed or employed in jobs that have nothing to do with their training. Moreover, recent research has demonstrated that students in a variety of subjects fail to learn the basic skills and abilities (e.g., critical thinking skills) that colleges claim to develop and organizations claim that they require in new hires (Arum \& Roksa, 2011). As numerous critics of higher education have pointed out, the BA needs to be more than a rough indicator of raw intelligence. Otherwise, organizations may as well select straight out of high school and train workers themselves. 
Consequently, we argue that colleges need to do more to ensure that they are fulfilling their stated missions. We know too much about training and development not to apply our knowledge to our field of work. Colleges should develop programs targeting the development of not only jobrelevant KSAs but also of the soft skills necessary to become more employable across a variety of jobs. Moreover, it needs to be recognized that the liberal arts have an important role to play in this mission in terms of developing character (Hanson, Heath, \& Thornton, 2001; Winter, McClelland, \& Stewart, 1981). Colleges should treat this aspect of their mission every bit as seriously as job-specific training. In other words, coursework needs to be targeted at the virtues, the values, and the mindset that make an individual a good citizen in order to be effective in the goal of character development (Hanson \& Heath, 1998).

Furthermore, a focus on developing both skills and character needs to be more than words. There is a real need for concrete assessments of the degree to which colleges are succeeding in these endeavors. For too long the difficulties in measuring change in these characteristics and skills have allowed colleges to avoid specific targeting of their development. Recent pressure to demonstrate the character development aspects of their missions by accrediting bodies may tempt some colleges to remove them from their missions. We believe that this would be a mistake. Students from schools that can provide evidence of developing employability will be more competitive in the job market, and the schools themselves will be rewarded with increased student demands.

I-0 psychology - With the previous paragraph in mind, we need to reflect on our own profession and our own efforts to train others in our disciplines. What can we do to increase the employability of I-O psychology students? How do we move from providing information to developing real skills and characteristics that make our own students more employable? We cannot act as scolds for our academic institutions and society at large when we ourselves are not using our own knowledge to improve our processes. Consequently, we would like to make the argument that the Society for Industrial and Organizational Psychology itself become involved in designing a means by which the effectiveness of training can be compared across institutions and ensure that minimum standards are being met.

Added rigor in our training can only help us as a field. If we are to take the challenge of developing employability seriously, we need to begin in our classrooms and in the organizations we work in.

\section{Conclusion}

Hogan, Chamorro-Premuzic, and Kaiser have provided a useful model for understanding employability. We expanded on the vital point that both the character and the KSA elements of their employability model can be developed and that they are developed through work experiences. However, we have generally not been intentional about this development process. Plus we have really only focused our efforts on those for whom employability isn't a problem. We believe that progress on the employability problem requires the acknowledgement that personality traits can and do change and the alignment of solutions in line with fostering these changes toward employability in business, societies, and in our own field.

\section{References}

Arum, R., \& Roksa, J. (2011). Academically adrift: Limited learning on college campuses. Chicago, IL: University of Chicago Press.

Haller, A. O., \& Portes, A. (1973). Status attainment processes. Sociology of Education, 46, 51-91.

Hanson, V. D., \& Heath, J. (1998). Who killed Homer? New York, NY: The Free Press.

Hanson, V. D., Heath, J., \& Thornton, B. (2001). Bonfire of the humanities. Wilmington, DE: ISI. 
Harms, P. D., Roberts, B. W., \& Winter, D. (2006). Becoming the Harvard man: Person-environment fit, personality development, and academic success. Personality and Social Psychology Bulletin, 32, 851-865.

Hogan, R., Chamorro-Premuzic, T., \& Kaiser, R. B. (2013). Employability and career success: Bridging the gap between theory and reality. Industrial and Organizational Psychology: Perspectives on Science and Practice, 6, 3-16.

Hudson, N. W., Roberts, B. W., \& Lodi-Smith, J. (2012). Personality trait development and social investment in work. Journal of Research in Personality, 46, 334-344.

Lodi-Smith, J., \& Roberts, B. W. (2007). Social investment and personality: A meta-analysis of the relationship of personality traits to investment in work, family, religion, and volunteerism. Personality and Social Psychology Review, 11, 68-86.

Paul, K., \& Moser, K. (2009). Unemployment impairs mental health: Meta-analyses. Journal of Vocational Behavior, 74, 264-282.

Roberts, B. W. (1997). Plaster or plasticity: Are work experiences associated with personality change in women? Journal of Personality, 65, 205-232.

Roberts, B. W., Caspi, A., \& Moffitt, T. (2003). Work experiences and personality development in young adulthood. Journal of Personality and Social Psychology, 84, 582-593.
Roberts, B. W., Bogg, T., Walton, K., \& Caspi, A. (2006). De-investment in work and non-normative personality trait change in young adulthood. European Journal of Personality, 20, 461-474.

Roberts, B. W., \& Robins, R. W. (2004). A longitudinal study of person-environment fit and personality development. Journal of Personality, 72, 89-110.

Roberts, B. W., \& Wood, D. (2006). Personality development in the context of the Neo-Socioanalytic Model of personality (Chapter 2, pp. 1139). In D. Mroczek \& T. Little (Eds.), Handbook of Personality Development. Mahwah, NJ: Erlbaum Associates.

Sewell, W. H., \& Hauser, R. M. (1980). The Wisconsin longitudinal study of social and psychological factors in aspirations and achievements. Research in Sociology of Education and Socialization, 1, 59-101.

Sewell, W. H., \& Hauser, R. M. (1992). The influence of Blau and Duncan's the American occupational structure on the Wisconsin model. Contemporary Sociology, 21, 598-603.

United Nations Development Programme. (2006). Poverty, unemployment, and social exclusion; http://www.undp.hr/upload/file/104/52080/ FILENAME/Poverty,Unemployment and Social Exclusion.pdf

Winter, D., McClelland, D., \& Stewart, A. (1981). A new case for the liberal arts. San Francisco, CA: Jossey-Bass. 